\title{
Therapeutic strategies in Wilson disease: pathophysiology and mode of action
}

\author{
Wolfgang Stremmel ${ }^{1} \wedge$, Ralf Weiskirchen $^{2} \wedge$ \\ ${ }^{1}$ Department of Gastroenterology, Medical Center Baden-Baden, Baden-Baden, Germany; ${ }^{2}$ Institute of Molecular Pathobiochemistry, Experimental \\ Gene Therapy and Clinical Chemistry, RWTH University Hospital Aachen, Aachen, Germany \\ Contributions: (I) Conception and design: Both authors; (II) Administrative support: None; (III) Provision of study materials or patients: None; (IV) \\ Collection and assembly of data: Both authors; (V) Data analysis and interpretation: Both authors; (VI) Manuscript writing: Both authors; (VII) Final \\ approval of manuscript: Both authors. \\ Correspondence to: Wolfgang Stremmel. Department of Gastroenterology, Medical Center Baden-Baden, Baden-Baden, Germany. \\ Email: wolfgangstremmel@aol.com.
}

\begin{abstract}
Wilson disease is a copper overload disease treatable with the chelators D-penicillamine and trientine to enhance urinary excretion or with zinc which predominantly inhibits absorption. By lifelong treatment a normal life expectancy and significant improvement of hepatic injury as well as neurologic manifestation is achievable. Here we evaluate the mode of action for effective therapy of Wilson disease. We postulate that there is no quantitative removal of copper from the liver possible. The therapeutic goal is the removal of toxic free copper (non-ceruloplasmin, but albumin bound copper). This is achievable by the induction of metallothionein which is accomplished by chelators and in particular by zinc. For control of therapy the option of a direct measurement of free copper would be preferable over the less reliable calculation of this fraction. A therapeutic challenge is still the full restoration of neurological deficits which can hardly be reached by the available chelators. Whether bis-choline-tetrathiomolybdate as intracellular copper chelator is an option has to be awaited. It is concluded that the goal of actual drug therapy in Wilson disease is the normalization of free copper in serum.
\end{abstract}

Keywords: Wilson disease; copper metabolism; copper chelators; zinc; free copper

Submitted Apr 02, 2020. Accepted for publication Jul 22, 2020.

doi: $10.21037 /$ atm-20-3090

View this article at: http://dx.doi.org/10.21037/atm-20-3090

\section{Introduction}

Wilson disease is a rare (1:30,000 inhabitants) inherited copper overload disease of the liver due to impaired biliary copper excretion. It affects female as well as male individuals and manifests mostly in late childhood or adolescence (1). It is an autosomal recessive disorder due to mutation of the $A T P 7 B$ gene located on the long arm of chromosome13 at position 14.3 (2).

Although the disease can be treated, the mechanism of action for therapy is not completely understood. Therefore, we describe here what is known about Wilson disease and put a view on treatment mechanism in perspective. The key question is whether chelators or zinc indeed remove copper from the organism or turn toxic copper into harmless deposits.

\section{Methods}

The literature was searched via PubMed according to the listed key words. We considered German and English original publications (basic science and clinical) and reviews of the last 30 years.

\footnotetext{
^ ORCID: Wolfgang Stremmel, 0000-0002-8545-1753; Ralf Weiskirchen, 0000-0003-3888-0931.
} 


\section{Physiology}

The gene product is the ATPase which carries cytoplasmatic copper to the trans-Golgi-network (TGN) for incorporation into apoceruloplasmin with 8 copper binding sites before it is released as ceruloplasmin at the basolateral side of hepatocytes to the systemic circulation (2). As copper containing oxidase it is responsible for transfer of $\mathrm{Fe}^{2+}$ to $\mathrm{Fe}^{3+}$ which is incorporated into transferrin for iron delivery to the system utilizing transferrin receptors (3). When more copper is transported to the TGN it is released by vesicular transport to the canalicular plasma membrane for release into bile from where excess copper is excreted in stool. Intestinal-released copper is hardly be reabsorbed due to binding to bile acids, i.e., taurochenodeoxycholate $(4,5)$. Absorption from diet is carrier-mediated, transporting $\mathrm{Cu}^{+}$ via the copper transporter (Ctr1) at the apical site to cytosol followed by intracellular binding to metallothionein and release at the basolateral side of mucosal cells via ATP7A (Menkes ATPase) (6). Since only $\mathrm{Cu}^{+}$is transportable, a conversion of $\mathrm{Cu}^{2+}$ to $\mathrm{Cu}^{+}$has to occur for cellular entry. After release from mucosal cells copper is transported bound to albumin via portal blood to the liver from where it is extracted by Ctr1. Within hepatocytes the free cytotoxic $\mathrm{Cu}^{+}$is bound after uptake to the Antioxidant protein 1 (Atox1) from where it is handled to ATP7B for translocation to TGN (1). During phases of copper overload, excess $\mathrm{Cu}^{+}$is transiently bound and stored in a complex with metallothionein (1) (Figure 1).

\section{Pathophysiology}

In Wilson disease almost 800 different mutations of the $A T P 7 B$ gene are known (7-9), which result in functional impairment of copper transport to the TGN reaching from absent ATP7B in TGN (mutation H1069Q in exon 14) to failure of Atox1 binding to this transporter, impaired transmembrane translocation or release at the luminal side of TGN (Figure 2). The remaining, non-transportable cytoplasmatic copper piles up and is bound to metallothionein, the synthesis of which is induced by copper (10). When the copper binding capacity of metallothionein comes to its limit, excess copper is also deposited within lysosomes where due to the acid environment amorphous copper complexes accumulate, potentially inducing free radical injury $(11,12)$. These complexes are detectable histologically by Rhodamine staining (13). The toxic $\mathrm{Cu}^{1+}$ damages the lysosomal membrane, causes $\mathrm{Cu}^{1+}$ overflow to cytoplasm and thus, cellular damage concomitant with release to the circulation. The diminished copper transport through ATP7B to TGN results also in lack of biliary excretion and consequently hepatic copper overload (1). In addition insufficient apoceruloplasmin loading with copper results in its degradation. The resulting very low ceruloplasmin plasma concentration calls in for albumin as substitute to bind in addition to the copper absorbed from the intestine also released copper from damaged hepatocytes (Figure 1). However, the copper-binding capacity of albumin is limited. It seems that copper is only weakly bound and can dissociate for uptake in other organs (14). Therefore, copper can be released via kidneys to urine. This, non-ceruloplasmin bound (albuminassociated), free copper is thought also to be capable to pass to brain causing among other cerebral manifestation mostly motoric impairment. It could be hypothesized that copper penetrates at the site of plexus coroidei through fenestrated endothelium into brain and accumulates within the nearby basal ganglia. Other explanations for basal ganglia destruction claim that it is due to structural/ functional consequences caused by the mutated ATP7B because no neuronal copper deposition was noted in respective animal studies $(15,16)$. Mechanistically, the consequent inhibition of ceruloplasmin biosynthesis due to mutated ATP7B protein (in liver as well as in brain) disturbs cellular iron release with excess intracellular iron deposition, especially in the basal ganglia (17-19). Accordingly, it needs further evaluation whether the mutated ATP7B or copper/iron accumulation are responsible for neurological manifestation. Copper and iron overload are potentially reversible by liver transplantation due to concomitant ceruloplasmin normalization. However, mutated ATP7B remains and could explain persistent neurological symptoms.

Copper accumulation in the cornea appears as goldenbrown rings around the edge of the eye lenses are called Kayser-Fleischer rings. They do not impair vision $(1,20)$. Copper accumulation in kidneys and heart are rarely observed causing tubulopathy and cardiomyopathy, respectively. Continuous hepatic injury eventually leads to cirrhosis and portal hypertension. The enlargement of the spleen causes accompanying thrombocytopenia and sometimes leucopenia and anemia as consequence of hypersplenism. In addition latent or overt hemolysis with unconjugated hyperbilirubinemia can occur (20). This Coombs-negative hemolysis is considered as a consequence of $\mathrm{Cu}^{+}$-mediated erythrocyte injury (1). A prominent hemolysis occurs frequently on the occasion of fulminant 


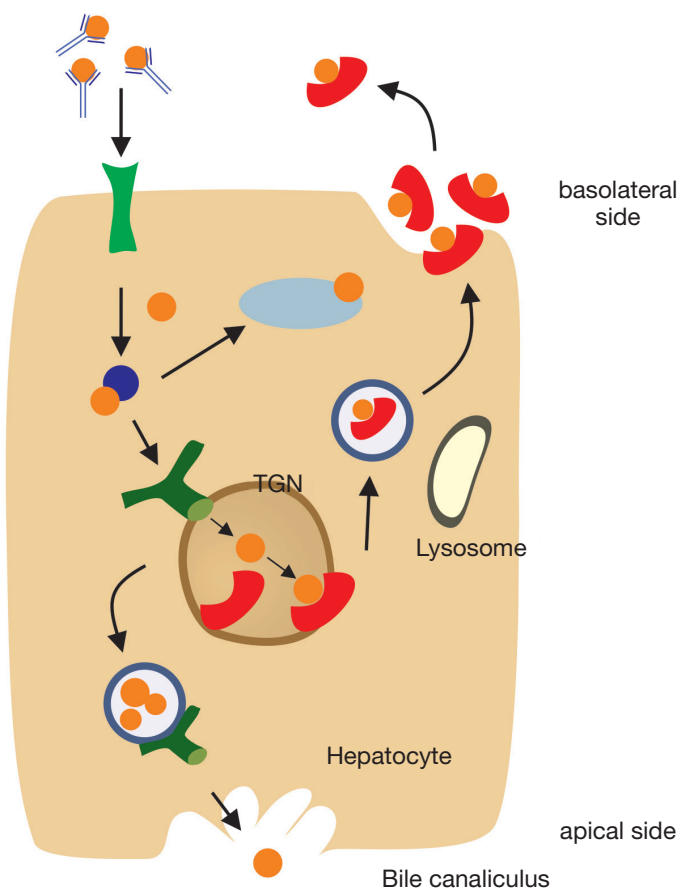

Physiological condition

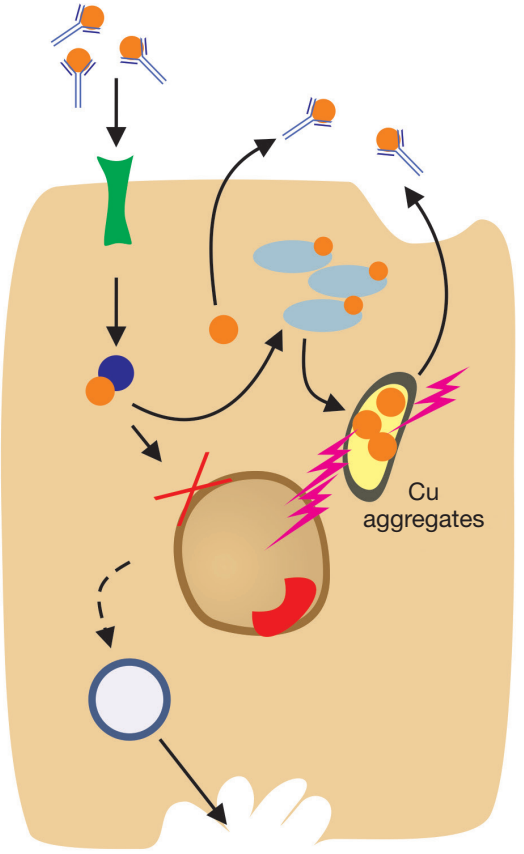

Wilson disease

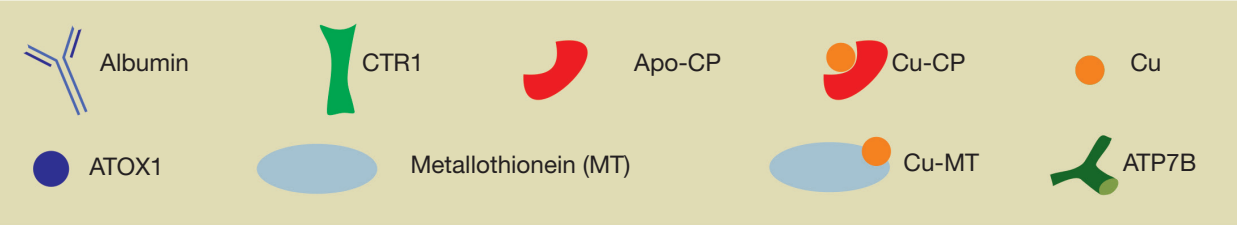

Figure 1 Physiology and pathophysiology of copper transport and metabolism. Under physiological conditions (left panel), copper uptake in hepatocytes is initiated by the high affinity Ctr1 from the apical side. In the cytosol, copper binds to the chaperon ATOX1 that handles copper to ATP7B as transporter into the trans-Golgi network (TGN). There it is incorporated into apoceruloplasmin and released as copper loaded ceruloplasmin via vesicular export at the basolateral plasma membrane into the blood stream. As alternative pathway, the nonceruloplasmin copper is secreted by exocytosis and via ATP7B at the canalicular membrane to bile. Non-transported copper is intermittently stored in cytosol within metallothionein. In Wilson disease (right panel), functional ATP7B is missing resulting in backing-up of copper in cytosol. When the metallothionein binding capacity is exceeded, the copper overspill is covered in lysosomes which eventually burst under the burden of generated free radicals. It induces cell injury and release of free copper to blood.

Wilson disease with acute hepatic failure due to copperinduced apoptosis (21). At this occasion, a concomitant massive release of copper to the circulation occurs.

All of this leads to a plethora of symptoms (20) (Figure 3). Systematic analyses of large patient-cohorts did not define specific genotypes which are responsible for different manifestations, e.g., mainly hepatic, neurologic, mixed manifestations, fulminant or asymptomatic courses (22-25). Moreover, of the different proteins involved in copper metabolism, only $A T P 7 B$ mutations were shown to be responsible for manifestation of human Wilson disease $(22,23)$. Even aceruloplasminemia is different to the clinical presentation in Wilson disease. It reveals severe iron deficiency and neurodegenerative features but normal biliary copper excretion (24).

However, modulating epigenetic factors, are believed to be responsible for the time and type of clinical manifestation. One hypothetical option could be the metallothionein gene family, the expression of which may modulate intracellular free copper availability (26). 


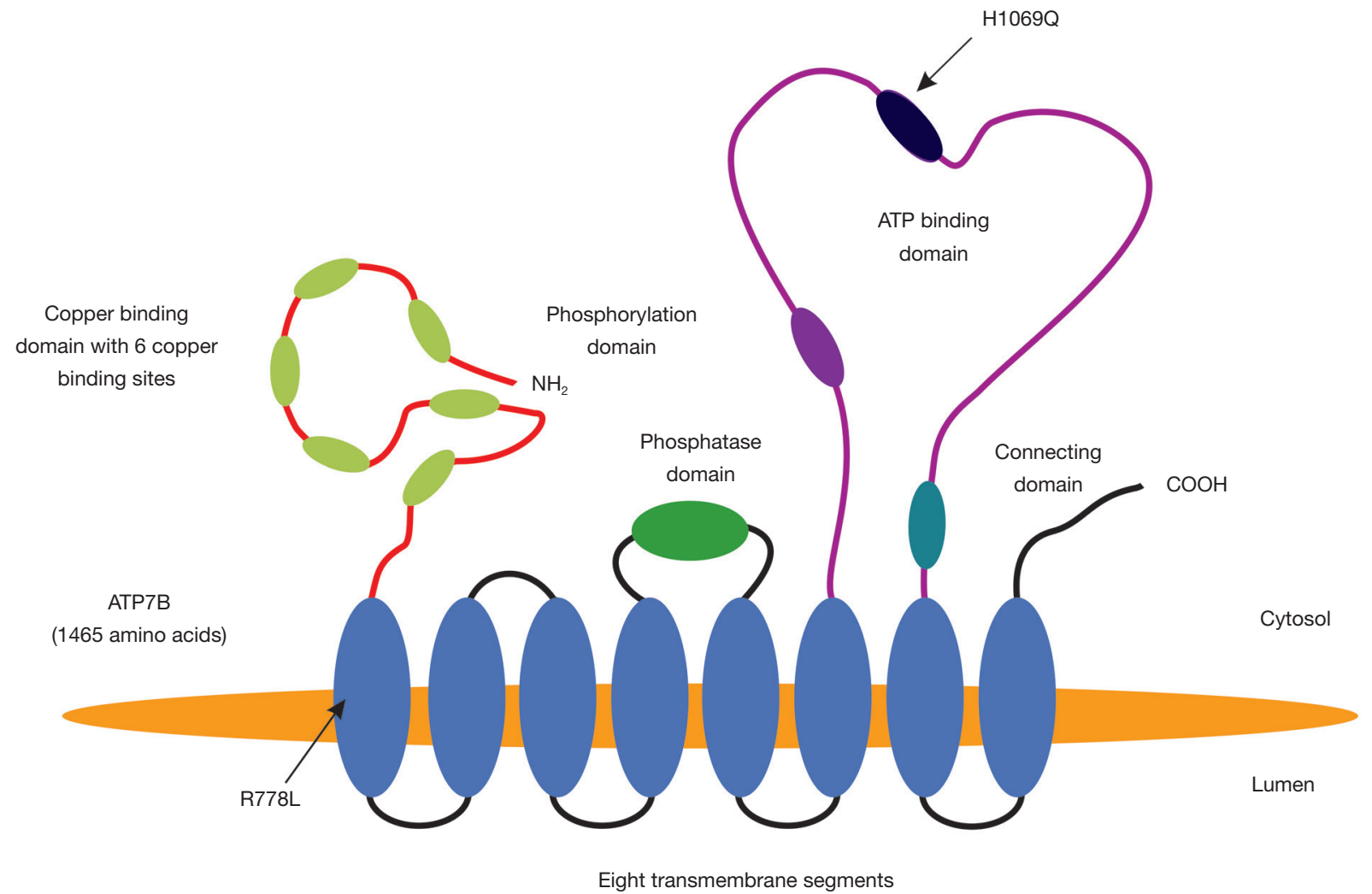

Figure 2 The conformation of the ATP7B protein and marking of 2 prominent mutations. In humans the mature copper-transporting ATP7B protein consists of 1,465 amino acid encompassing a copper binding domain with six copper binding sites, a phosphatase domain, a phosphorylation domain, an ATP-binding domain, and a short stretch connecting the ATP binding domain to the eight transmembrane segments (2,8). The positions of the two most common mutations R778L (located in the first transmembrane region affecting transport of copper through the membrane) and H1069Q (located in the ATP binding site reducing ATP-mediated phosphorylation) are depicted. However, it is also discussed that mutations induce protein misfolding resulting in endoplasmic-reticulum (ER)-associated degradation (9).

\section{Diagnosis}

Based on the pathophysiology, diagnostic criteria for Wilson disease are: low ceruloplasmin, low serum copper, elevated free (albumin-bound) copper [as calculated by the formula: free copper $=$ serum copper $(\mu \mathrm{g} / \mathrm{dL})$ minus ceruloplasmin $(\mathrm{mg} / \mathrm{dL}) \times 3.15$ ], and elevated urinary copper excretion (Table 1) $(27,28)$. Gold standard is the quantitative determination of liver copper (27). Positive histological Rhodamine stain identifies lysosomal copper aggregates (13). Genetic analysis can be helpful to detect homozygous or compound heterozygous disease causing mutations of the $A T P 7 B$ gene (23). A great number of mutations have been reported that hamper the proper function of the ATP7B. Actually more than 800 pathogenic variants in the $A T P 7 B$ gene have been identified, with single-nucleotide missense and nonsense mutations being the most common, followed by small deletions, splice site mutations and small insertion (29). Kayser-Fleischer rings are detectable in only $50 \%$ of the patients, but mostly $(\sim 80 \%)$ in neurological cases (Table 1). According to the most relevant diagnostic features a Wilson disease-specific score has been developed (Table 2) (22). It is of further relevance whether and to what level transaminases are elevated as indicator of liver injury.

Signs of cirrhosis reflect advanced chronic liver disease even in young patients. A neurological work-up is required to determine the extent of central nervous system (CNS) manifestations. Finally it is important to evaluate whether the patient has other disorders, particularly those affecting the liver. For differential diagnosis copper overload due to cholestasis, e.g., primary sclerosing cholangitis (PSC) or primary biliary cholangitis (PBC) has to be 


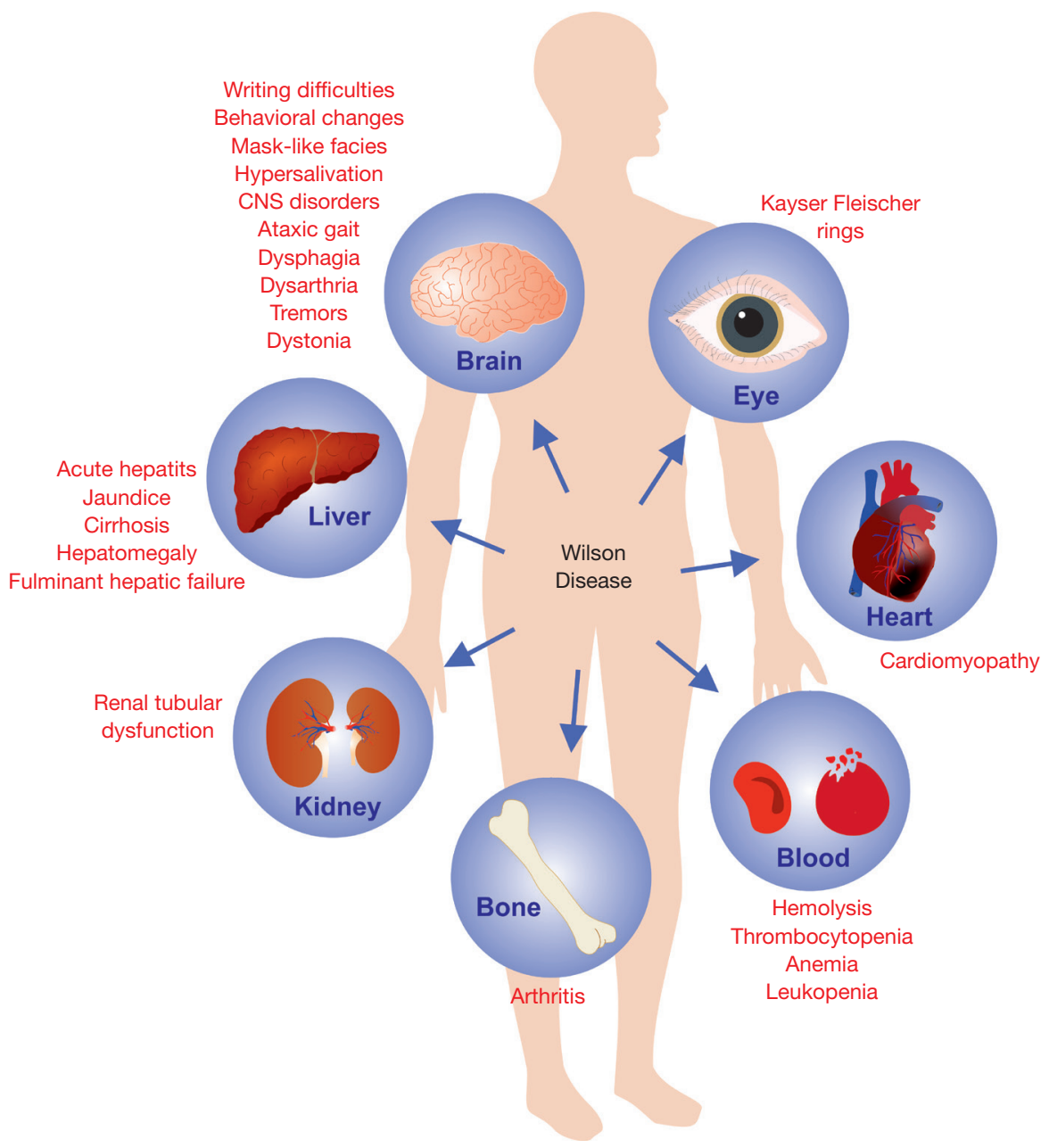

Figure 3 Plethora of organ manifestations and symptoms in Wilson disease. In Wilson disease the symptoms are highly variable and can affect liver, brain, kidney, eyes, heart, bone, blood system, and many other organs or tissues.

Table 1 Diagnosis of Wilson disease

\begin{tabular}{ll}
\hline Parameter & Criteria to diagnose Wilson disease \\
\hline Ceruloplasmin & $<0.2 \mathrm{~g} / \mathrm{L}$ \\
Serum copper & $<70 \mu \mathrm{g} / \mathrm{dL}(12 \mu \mathrm{mol} / \mathrm{L})$ \\
Urinary copper & $>60 \mu \mathrm{g} / \mathrm{d}(>0.94 \mu \mathrm{mol} / \mathrm{d})$ \\
Free copper & $>15 \mu \mathrm{g} / \mathrm{dL}(0.23 \mu \mathrm{mol} / \mathrm{dL})$ \\
D-penicillamine 500 & Urinary copper increase to $>1,600 \mu \mathrm{g} / \mathrm{d}$ \\
Liver copper & $>250 \mu \mathrm{g} / \mathrm{d}$ dry weight \\
Kayser-Fleischer-rings & Sensitivity $50 \%$; Specificity $95 \%$ \\
Genetic analysis & Sensitivity $90 \%$; Specificity $100 \%$ \\
\hline
\end{tabular}


Table 2 Scoring system developed at the $8^{\text {th }}$ International Meeting on Wilson's disease, Leipzig 2001 [modified from (30)]

\begin{tabular}{|c|c|}
\hline Typical clinical symptoms and signs & Score \\
\hline Kayser-Fleischer rings & - Absent: 0 \\
\hline \multirow{2}{*}{$\begin{array}{l}\text { Neurologic symptoms or typical imaging at brain magnetic } \\
\text { resonance imaging }\end{array}$} & - Severe: 2 \\
\hline & - Mild: 1 \\
\hline \multirow[t]{3}{*}{ Serum ceruloplasmin } & - Normal $(>0.2 \mathrm{~g} / \mathrm{L}): 0$ \\
\hline & - Slightly reduced $(0.1-0.2 \mathrm{~g} / \mathrm{L}): 1$ \\
\hline & - Drastically reduced $(<0.1 \mathrm{~g} / \mathrm{L}): 2$ \\
\hline Coombs negative hemolytic anemia & - Present: 1 \\
\hline \multirow{3}{*}{ Liver copper (in the absence of cholestasis) } & - 0.8-4 $\mu \mathrm{mol} / \mathrm{g}: 1$ \\
\hline & - Normal $(<0.8 \mu \mathrm{mol} / \mathrm{g}):-1$ \\
\hline & - Rhodamine-positive granules: +1 (if no quantitative liver copper is available) \\
\hline \multirow[t]{4}{*}{ Urinary copper (in the absence of acute hepatitis) } & - Normal : 0 \\
\hline & - 1-2× ULN: 1 \\
\hline & - $>2 \times$ ULN: 2 \\
\hline & - Normal, but $>5 \times$ ULN after one day challenge with $2 \times 0.5 \mathrm{~g}$ DPA: 2 \\
\hline
\end{tabular}

Abbreviations used: DPA, D-penicillamine; ULN, upper limit of normal.

considered beside other very rare disorders (31). The aceruloplasminemia is not associated with Wilson disease because there is an unimpaired biliary release of copper (32). Heterozygous carrier of $A T P 7 B$ mutations show only a slight low ceruloplasmin and serum copper but a normal urinary copper excretion $(32,33)$. They do not develop clinical symptoms, in particular liver damage and neurological symptoms. Most likely heterozygous carriers do not have elevation of free copper, because phenotypic expression of the pathophysiology is mild, i.e., only marginal ceruloplasmin suppression. In cases with only discrete low ceruloplasmin $(<0.2 \mathrm{~g} / \mathrm{L})$, the calculation of non-ceruloplasmin bound copper is not reliable. The reason is that most laboratories determine ceruloplasmin by an immunonephelometric method which measures both ceruloplasmin and the biologic inactive apoceruloplasmin. The enzymatic method (copper oxidase) is more accurate (34). It is our experience that the calculation of free copper is only valid at ceruloplasmin concentrations below
$0.1 \mathrm{~g} / \mathrm{L}$. Unfortunately, the direct measurement of the free copper fraction is not available yet for routine laboratory testing although it would be most desirable for diagnosis and therapy monitoring (35).

\section{Prognosis}

The prognosis of untreated Wilson disease patients is poor with a median life expectancy of 40 years (36).

Today with all of the available therapeutic regimens, a normal life expectancy of patients with Wilson disease is achievable (Figure 4A) (20). In addition clinical, neurological, and hematological symptoms improve during treatment to a significant extent (Figure 4B,C,D) (20). Exceptions are those indicating impaired liver function due to cirrhosis and complications of portal hypertension (37). Most challenging are neurologic disorders, which are only partial reversed and in rare cases may even deteriorate which may be due to inefficient access of present therapies to brain copper 
A

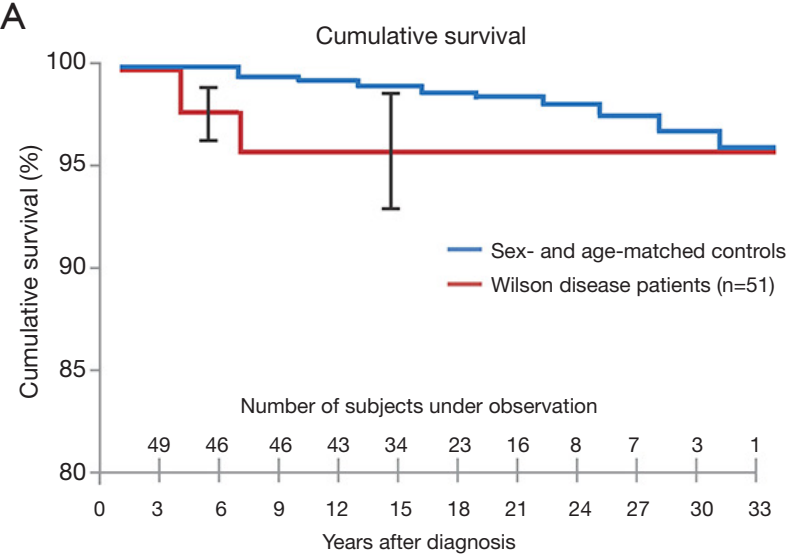

C

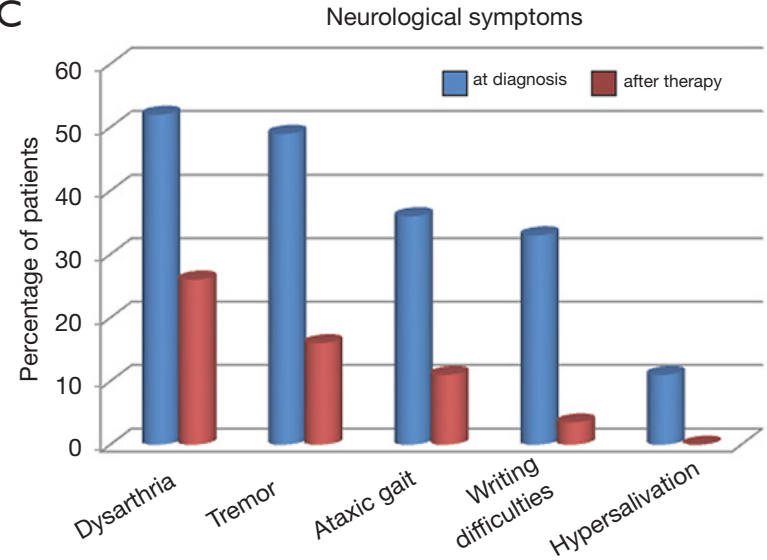

B

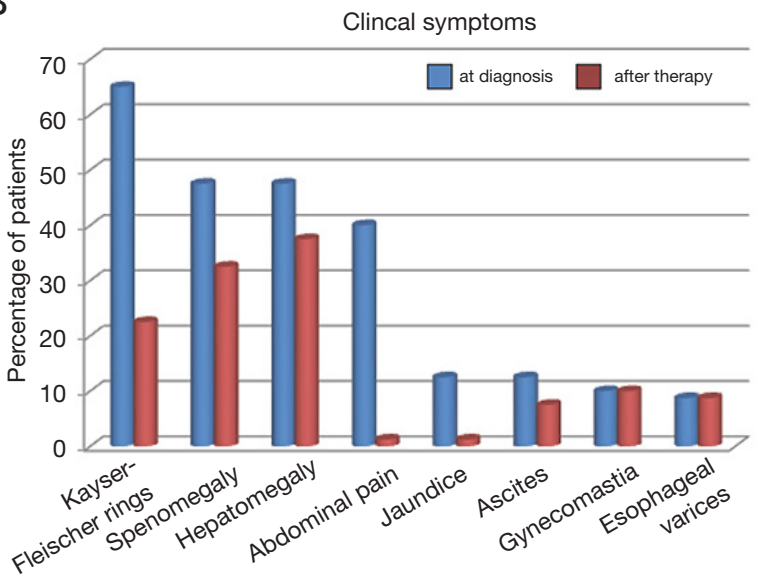

D

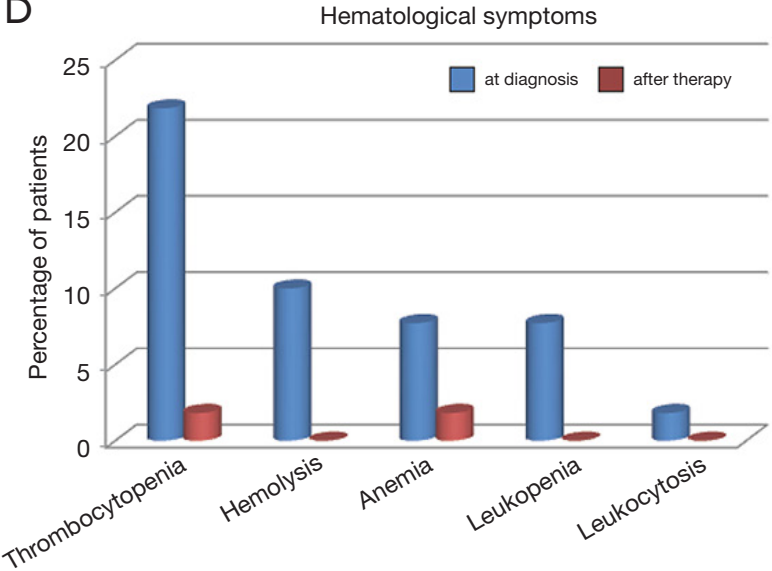

Figure 4 Therapeutic efficacy in therapy of Wilson disease. (A) The life expectancy of Wilson disease patients is normal if therapy is started in a timely manner. Shown is the cumulative survival in 51 patients with Wilson disease compared with that of an age- and sex-matched control population. The survival time was only slightly reduced during the early period of observation when liver transplantation was not available for fulminant hepatic failure. Otherwise the survival rates were not different after 15 years of observation. Improvement of (B) clinical, (C) neurological, and (D) hematological symptoms before after long-term treatment with the de-coppering drug D-penicillamine. Data depicted were taken from (20).

and iron or due to the mutated neuronal $A T P 7 B$.

\section{Therapy}

\section{Diet}

A therapy with a low copper diet is inefficient because it is very difficult to achieve a negative copper balance since almost every food contains traces of copper to be absorbed via Ctr1. However, it is recommended to avoid food rich in copper to support medical therapy, like cacao, dark chocolate, nuts, raisins, shellfish, oysters, inner organs like liver and kidneys, dietary supplements such as spirulina, and shitake mushrooms (38).

\section{Drug therapy of Wilson disease}

It is a general shortcoming that for none of the therapies applied in Wilson disease randomized controlled trials (RCT) were performed. Most patients are treated with copper chelators to remove copper from albumin (27). D-penicillamine was the first copper chelator on the market. It binds extracellular copper and excretes it via kidneys to urine. Due to interference with pyridoxin action, it has to be given in combination with $25-50 \mathrm{mg}$ vitamin B6. D-penicillamine is powerful to improve the disease (20). 
Table 3 Adverse events of D-penicillamine, trientine and zinc

\begin{tabular}{|c|c|c|c|}
\hline Occurrence time & D-penicillamine & Trientine & Zinc \\
\hline Early & - Rash & & \multirow{7}{*}{$\begin{array}{l}\text { - Dyspepsia } \\
\text { - Pancreatic enzyme elevation }\end{array}$} \\
\hline \multirow[t]{6}{*}{ Late } & - Cytopenia & \multirow{6}{*}{$\begin{array}{l}\text { - Aplastic and sideroblastic } \\
\text { anemias }\end{array}$} & \\
\hline & - Nephrotoxicity & & \\
\hline & - Polymyositis & & \\
\hline & - Myasthenia gravis & & \\
\hline & - Collagen disorders & & \\
\hline & - Sensory polyneuropathy & & \\
\hline
\end{tabular}

Within 1-2 years the patients become normal in regard to free copper (calculable at ceruloplasmin $<0.1 \mathrm{~g} / \mathrm{L}$ ) and normal urinary copper excretion determined after 2 days of chelator cessation and urinary collection at $3^{\text {rd }}$ days without chelator (Table 1) (39). At that time transaminases should also be normalized.

The dosage starts slowly with $300 \mathrm{mg} / \mathrm{d}$ and is increased weekly by $300 \mathrm{mg}$ up to $1,500 \mathrm{mg} / \mathrm{d}$ as required. After reaching remission with normal free copper and urinary copper excretion, therapy has to be maintained lifelong at lowest possible doses (mostly $600-900 \mathrm{mg} / \mathrm{d}$ ) (27). In some cases $(14 \%$,$) an initial deterioration of neurological$ symptoms is observed, but the pathophysiology remains unclear (40). One hypothesis claims that a sudden release of copper from hepatic stores is responsible. Unfortunately, this neurologic deterioration is difficult to reverse (40). There is a number of other adverse events occurring in the initial phase of treatment and on long term therapy (Table 3). Initial allergic reaction can be copied by cessation of D-penicillamine or a concomitant therapy with steroids. For long-term treatment the adverse reactions and their severity have to be weighed against the efficacy of therapy. Often induction of autoimmune disorders of different degrees is noted with elevation of antinuclear antibodies (ANA) (27). In these cases therapy has to switch to trientine or zinc.

Trientine $2 \mathrm{HCl}$ is the chelator only for patients intolerant to D-penicillamine (27). After slowly escalating doses it can be increased to $1,800 \mathrm{mg}$ trientine/d as required, while for maintenance therapy $600-1,000 \mathrm{mg}$ trientine/d are mostly applied. Trientine $2 \mathrm{HCl}$ does not require the addition of vitamin B6. It is as effective as D-penicillamine and has less adverse events (40). Still neurologic deterioration can occur and anemia has been reported (41-43). Since 2018, also trientine $4 \mathrm{HCl}$ is available on the market (44). It can also only be prescribed for patients intolerant to D-penicillamine.

Zinc is less dangerous in regard to adverse events (45). Only abdominal discomfort was recorded which in severe cases leads to its discontinuation. On the market are zinc salts or better tolerable zinc-amino acid bound preparations.

The efficacy is established in particular for long term maintenance therapy (46). As initial therapy it may slow down the disease activity. For control of liver damage, it was reported to be inferior to chelators $(27,45-47)$. The recommended dose for adults is $3 \times 50 \mathrm{mg}$ daily and for children and adolescents $3 \times 25 \mathrm{mg}$ daily (48).

Only in rare cases zinc is combined with chelators, both in reduced doses. It has to be provided separate from food and chelators to avoid in gut intraluminal binding and, thus, absorption. This requires a disciplinary drug intake schedule for the patient. Exact evaluation of this recommended intake scheme is not available and only based on theoretical consideration.

For determination of the therapeutic efficacy of zinc, again free copper, urinary copper excretion (without disruption of the therapy) and transaminase normalization are valuable tools. In addition, urinary zinc can be determined to prove the compliance of the patient.

In initial clinical trials, bis-choline-tetrathiomolybdate (TTM) is currently evaluated (49). It acts like a copper chelator, operating within the cells by binding copper associated to proteins in stable complexes which are excreted via bile $(50,51)$. It also seems to be taken-up into neurons for recovery from copper induced cell damage by binding of excess protein bound copper. In blood it binds albumin-bound copper (50). The consequent disposal remains open. The 
clinical results in regard to neurological improvement were impressive (49). However, in a substantial portion of patients an elevation of transaminases was observed $(49,50)$. This was also the case in earlier studies using the TTM ammonium salt where in addition aplastic syndromes were reported (51). It may be due to its intracellular availability. The new bischoline-TTM is more stable than the TTM ammonium salt and shows better bioavailability. Further trials with the new bis-choline-TTM have to awaited and evaluated.

\section{Other therapeutic strategies}

In fulminant hepatic failure, liver transplantation is the first choice of therapy. The success rate of the operation in Wilson disease is rather high compared to other causes of acute hepatic failure (52). Still a mortality rate of $10-20 \%$ within the first year after transplantation is too high to recommend this procedure for the general Wilson disease population, particularly because good drug therapy options are available which are associated with an unimpaired prognosis compared to the normal age adapted population (Figure 4A) (20). Challenging is the observation that with transplantation the liver disease is cured and does not require further copper controlling therapy (30). The question arises whether neurologic symptoms also disappear due to normalization of ceruloplasmin in blood, while the genetic defect in brain persists. Indeed the observations of neurologic improvement after liver transplantation are ambiguous (53).

Sophisticated gene therapy approaches for replacement of the mutated $A T P 7 B$ were successful in animal models of Wilson disease (54-60). This is another promising approach which should be explored in human Wilson disease.

As therapeutic goal remains the tackling of persistent neurologic symptoms which are not always improved by present therapies (Figure 4C). The reason may be an insufficient targeting of chelators across the bloodbrain-barrier towards copper loaded neurons. There are now attempts underway to generate blood-brain barrier formulations which may gain access to the brain (61).

\section{General consideration regarding therapeutic goals}

The goal of therapy could be the removal of excessive copper. Whether this is realistic, remains open. The liver copper content increases during manifestation of the disease and in most cases does not change thereafter, even under therapy $(62,63)$.

Anectodical experience of liver copper determination during therapy demonstrated no significant decrease of the copper load although there are no robust data available. However, the difference of urinary release (estimated mean of $250 \mu \mathrm{g} / \mathrm{d}$ under long term chelator therapy) and copper absorption (estimated mean of $100 \mu \mathrm{g} / \mathrm{d}$ ) does not account for significant copper depletion. Moreover, it has to be considered that excretion under chelator therapy decreases with time of treatment. Absorption depends on copper, zinc and fiber content in diet and the therapy dependent metallothionein induction.

A conservative estimate of the liver copper content assumes in Wilson disease $250 \mu \mathrm{g} / \mathrm{g}$ dry weight corresponding to $1,050 \mu \mathrm{g}$ copper/g wet weight (64) and a median liver weight of $1.5 \mathrm{~kg}$ according to $1.575 \mathrm{~g}$ copper (normal $0.29 \mathrm{~g}$ ) in the liver. If a netto loss of $150 \mu \mathrm{g}$ copper per day would be achievable, e.g., by chelator therapy, it would last 23.5 years to deplete copper from liver to normal values. According to our experience urinary copper excretion is normalized within about 2 years of chelator therapy, when determined after a drug holiday for 2 days. Thus, the persistent enhanced urinary copper excretion under chelator therapy may not originate from the liver but most likely from absorbed dietary copper which is loosely bound to albumin (free copper) and chelated e.g., by D-penicillamine for urinary excretion. Thus, it is unlikely that copper can be depleted from the liver.

However, there is almost normalization of free copper in serum concomitant with cessation of liver damage (significant improvement or even normalization of transaminases). Therefore it is concluded that the reduction of free copper in serum is the better therapeutic goal which is realistic to be achieved. To maintain a normal free copper, the chelator therapy should be maintained at best with the lowest chelator dose necessary, but it should never be discontinued. In case the therapy is broken up it was shown to lead to elevated free copper causing eventually fulminant Wilson disease with acute liver failure within a median of 1-2 years (27).

Enhanced free copper excretion in urine is the one obvious mode of action of chelator therapy. Moreover, the reported induction of metallothionein is the other mode of action of chelators to keep copper in an innocent bound state in the liver $(65,66)$. This can also be achieved efficiently by oral zinc substitution mainly operating in the liver as well as in the gut. In the intestine metallothionein bound copper is lost by physiologic desquamation of mucosal cells every 3-5 days (67), which results in loss of copper from the organism supporting the depletion of copper depositions 
similar as a copper free or reduced diet. This therapy is considered less effective compared to the chelator-induced loss in urine, at least at the beginning of treatment.

However, depletion of copper from the organism may only be of minor significance and may not be achievable due to pathophysiology and the above mentioned considerations. For use of the most harmless maintenance therapy, zinc would be preferred to chelator or new upcoming drugs with potential more adverse events. However, zinc is known to cause dyspepsia. Therefore, it should be taken in the least, but effective dose of 3-times $50 \mathrm{mg}$.

It could even be considered whether consumption of food rich in zinc may be of therapeutic use. This is provocative because food rich in zinc is also declared as avoidable in Wilson diseases $(38,66,68)$. Consequently, only acceptable are those with not as much copper: meat (except liver and kidney), vegetables, dairy, eggs, whole grains and potatoes $(66,68)$. Food with high content of phytates present in vegetables (i.e., vegan diet) inhibit absorption of zinc and other minerals. Zinc sources from animal food are best bioavailable: meat, dairy and eggs (68).

\section{Discussion}

We proposed in this review that the goal of therapy is the removal of toxic copper, because it causes free radical injury in the liver leading finally to cirrhosis. The occurrence of excessive free copper is due to lack of transport of cytoplasmatic copper to the TGN for incorporation into apoceruloplasmin as well as biliary excretion. The reason behind this is the mutated ATP7B. The consequent backlog of cytoplasmatic copper induces metallothionein which binds toxic copper within a harmless complex. With time, the liver is packed with copper. Indeed the maximal liver copper content is observed in this accumulation phase, where liver damage may not be present (normal transaminases). Thereafter, any overspill of copper will end in lysosomes which with time burst due to overload and free radical injury. This causes cell damage and release of copper to the circulation where it is loosely bound to albumin. This "free" copper is easily dissociable for urinary excretion and for deposition in other organs, e.g., the brain.

This proposed mechanism of therapeutic action to remove the free copper does not necessarily require a depletion of hepatic copper, which anyway would last a couple of decades. There is certainly a reduction of the copper burden possible, but for prevention of liver damage may not be required. It can at present only be achieved by therapy with the chelators D-penicillamine and trientine as well as with zinc. Remarkably, both strategies induce metallothionein as the key protein for protection against $\mathrm{Cu}^{+}$. It was reported that tetra-thiomolybdate as intracellular chelator removes copper from metallothionein ("stripping" effect). This could indicate that this metallothionein remains open for copper binding. To remove free copper as therapeutic aim is yet not commonly accepted. The shortcoming of this hypothesis is the lack of experimental evidence. It would be desirable to determine over the course of treatment the actual free copper concentration and correlate it to transaminases.

In case there is no irreversible liver damage, i.e., cirrhosis, one would predict a normalization of both parameters (i.e., free copper and transaminases) at the same time. The determination of the liver copper content would most likely remain identical. However, to perform liver biopsies only for this scientific purpose is not ethical. The retrospective analysis of copper content values obtained for different indications in Wilson disease patients could be helpful.

The final therapeutic goal would be gene therapy. However, in this field no real progress is visible at present. The liver transplantation was considered as a gene therapy, but only for the liver. It is possible that the establishment of a normal copper metabolism with normal ceruloplasmin prohibits damage through free copper. However, the experiences of neurologic improvement after transplantation are not unequivocal (53). There are positive and negative outcomes reported. Improvement might be due to iron and copper removal, whereas unchanged neurological presentation could be due to already irreversible brain damage or the interesting observation that the mutated ATP7B per se leads to neuronal destruction $(15,16)$.

\section{Summary}

It is a big achievement of the presently available drugs to allow patients with Wilson disease a normal life expectancy, although neurologic symptoms may persist. The improvement of liver function tests is likely due to removal of the toxic free copper. The direct determination of this copper fraction in serum would be a desirable tool to control the efficacy of the therapy (35). At present free copper concentration can only be calculated, whereas the normalization of urinary copper excretion is easily determined and most reliable. The depletion of liver copper is desirable but may not be realistic. As therapeutic 
tool, the chelators D-penicillamine and trientine as well as oral zinc preparations are available. Unfortunately, none of the available therapies have been examined in RCT's. Nevertheless, one of these therapies is mandatory for Wilson disease patients. Indeed the therapy has to be maintained lifelong with down titration to the lowest effective dose. Adverse events are not frequent and most of the patients tolerate them very well. Still a challenge is the therapeutic tackling of persistent neurologic symptoms.

\section{Acknowledgments}

Funding: None.

\section{Footnote}

Provenance and Peer Review: This article was commissioned by the Guest Editors (Ralf Weiskirchen and Wolfgang Stremmel) for the series "Unresolved Basic Issues in Hepatology" published in Annals of Translational Medicine. The article was sent for external peer review organized by the Guest Editors and the editorial office.

Peer Review File: Available at http://dx.doi.org/10.21037/ atm-20-3090

Conflicts of Interest: Both authors have completed the ICMJE uniform disclosure form (available at http://dx.doi. org/10.21037/atm-20-3090). The series "Unresolved Basic Issues in Hepatology" was commissioned by the editorial office without any funding or sponsorship. RW and Wolfgang Stremmel served as the unpaid Guest Editors of the series. RW serves as an unpaid editorial board member of Annals of Translational Medicine from Aug 2018-Jul 2022. The authors have no other conflicts of interest to declare.

Ethical Statement: The authors are accountable for all aspects of the work in ensuring that questions related to the accuracy or integrity of any part of the work are appropriately investigated and resolved.

Open Access Statement: This is an Open Access article distributed in accordance with the Creative Commons Attribution-NonCommercial-NoDerivs 4.0 International License (CC BY-NC-ND 4.0), which permits the noncommercial replication and distribution of the article with the strict proviso that no changes or edits are made and the original work is properly cited (including links to both the formal publication through the relevant DOI and the license). See: https://creativecommons.org/licenses/by-nc-nd/4.0/.

\section{References}

1. Stremmel W, Merle U, Weiskirchen R. Clinical features of Wilson disease. Ann Transl Med 2019;7:S61.

2. Bull PC, Thomas GR, Rommens JM, et al. The Wilson disease gene is a putative copper transporting P-type ATPase similar to the Menkes gene. Nat Genet. 1993;5:327-37. Erratum in: Nat Genet 1994;6:214.

3. Hellman NE, Gitlin JD. Ceruloplasmin metabolism and function. Annu Rev Nutr 2002;22:439-58.

4. Lewis KO. The nature of the copper complexes in bile and their relationship to the absorption and excretion of copper in normal subjects and in Wilson's disease. Gut 1973;14:221-32.

5. Gollan JL, Deller DJ. Studies on the nature and excretion of biliary copper in man. Clin Sci 1973;44:9-15.

6. Nose Y, Thiele DJ. Mechanism and regulation of intestinal copper absorption. Genes Nutri 2010;5:S11-4.

7. Park S, Park JY, Kim GH, et al. Identification of novel ATP7B gene mutations and their functional roles in Korean patients with Wilson disease. Hum Mutat 2007;28:1108-13.

8. Terada K, Schilsky ML, Miura N, et al. ATP7B (WND) protein. Int J Biochem Cell Biol 1998;30:1063-7.

9. Parisi S, Polishchuk EV, Allocca S, et al. Characterization of the most frequent ATP7B mutation causing Wilson disease in hepatocytes from patient induced pluripotent stem cells. Sci Rep 2018;8:6247.

10. Bhagavan NV. Mineral Metabolism- Metallothionein (chapter 37), pp. 873-900. Academic Press: Medical Biochemistry (Fourth Edition); 2002. ISBN: 978-0-12095440-7

11. Polishchuk EV, Polishchuk RS. The emerging role of lysosomes in copper homeostasis. Metallomics 2016;8:853-62.

12. Myers BM, Prendergast FG, Holman R, Kuntz SM, Larusso NF. Alterations in hepatocyte lysosomes in experimental hepatic copper overload in rats. Gastroenterology 1993;105:1814-23.

13. Wang B, Cui X, Zhang Z, et al. A six-membered-ring incorporated Si-rhodamine for imaging of copper(ii) in lysosomes. Org Biomol Chem 2016;14:6720-8.

14. Linder MC. Ceruloplasmin and other copper binding components of blood plasma and their functions: an update. Metallomics 2016;8:887-905.

15. Dong Y, Shi SS, Chen S, et al. The discrepancy between 
the absence of copper deposition and the presence of neuronal damage in the brain of Atp $7 \mathrm{~b}(-/-)$ mice. Metallomics 2015;7:283-8.

16. Jain S, Farías GG, Bonifacino JS. Polarized sorting of the copper transporter ATP7B in neurons mediated by recognition of a dileucine signal by AP-1. Mol Biol Cell 2015;26:218-28.

17. Mzhel'skaya TI. Biological functions of ceruloplasmin and their deficiency caused by mutation in genes regulating copper and iron metabolism. Bull Exp Biol Med 2000;130:719-27.

18. Klomp LW, Gitlin JD. Expression of the ceruloplasmin gene in the human retina and brain: implications for a pathogenic model in aceruloplasminemia. Hum Mol Genet 1996;5:1989-96.

19. Vassiliev V, Harris ZL, Zatta P. Ceruloplasmin in neurodegenerative diseases. Brain Res Brain Res Rev 2005;49:633-40.

20. Stremmel W, Meyerrose KW, Niederau C, et al. Wilson disease: clinical presentation, treatment and survival. Ann Intern Med 1991;115:720-6.

21. Strand S, Hofmann WJ, Grambihler A, et al. Hepatic failure and liver cell damage in acute Wilson's disease involve CD95 (APO-1/Fas) mediated apoptosis. Nat Med 1998;4:588-93.

22. Ferenci P, Stremmel W, Członkowska A, et al. Age and sex but not ATP7B genotype effectively influence the clinical phenotype of Wilson disease. Hepatology 2019;69:1464-76.

23. Chang IJ, Hahn SH. The genetics of Wilson disease. Handb Clin Neurol 2017;142:19-34.

24. Marchi G, Busti F, Lira Zidanes A, et al. Aceruloplasminemia: A severe neurodegenerative disorder deserving an early diagnosis. Front Neurosci 2019;13:325.

25. Simon I, Schaefer M, Reichert J, et al. Analysis of the human Atox 1 homologue in Wilson patients. World J Gastroenterol 2008;14:2383-7.

26. Karin M, Richards RI. The human metallothionein gene family: structure and expression. Environ Health Perspect 1984;54:111-5.

27. Ferenci P, Czlonkowska A, Stremmel W, et al. EASL Clinical Practice Guidelines: Wilson's disease. J Hepatol 2012;56:671-85.

28. Ferenci P, Ott P. Wilson's disease: Fatal when overlooked, curable when diagnosed. J Hepatol 2019;71:222-4.

29. The Human Gene Mutations Database (at the Institute of Medical Genetics in Cardiff), Available online: http://www. hgmd.cf.ac.uk. Last accessed 25 June, 2020.

30. Schilsky ML, Scheinberg IH, Sternlieb I. Liver transplantation for Wilson's disease: indications and outcome. Hepatology 1994;19:583-7.

31. Mayo Clinic Laboratories (USA). Test ID: CUT (Copper, Liver Tissue). Available online: https://www.mayocliniclabs. com/test-catalog/Clinical+and+Interpretive/8687. Last accessed 25 June, 2020.

32. Hermann W. Classification and differential diagnosis of Wilson's disease. Ann Transl Med 2019;7:S63.

33. Li H, Liu L, Li Y, et al. Familial screening of children with Wilson disease: Necessity of screening in previous generation and screening methods. Medicine (Baltimore) 2018;97:e11405.

34. Macintyre G, Gutfreund KS, Martin WR, et al. Value of an enzymatic assay for the determination of serum ceruloplasmin. J Lab Clin Med 2004;144:294-301.

35. Catalani S, Paganelli M, Gilberti ME, et al. Free copper in serum: An analytical challenge and its possible applications. J Trace Elem Med Biol 2018;45:176-80.

36. Wilson Disease (ATP7B) Sema 4 (2019). Available online: https://sema4.com/products/expandedcarrierscreen/ diseases-screened/wilson-disease-2/\#

37. Beinhardt S, Leiss W, Stättermayer AF, et al. Long-term outcomes of patients with Wilson disease in a large Austrian cohort. Clin Gastroenterol Hepatol 2014;12:683-9.

38. West H. 8 foods that are high in copper - evidence based. Healthline-Nutrition. 2018. Available online: https:// www.healthline.com/nutrition/foods-high-in-copper. Last accessed 1 April, 2020.

39. Hedera P. Clinical management of Wilson disease. Ann Transl Med 2019;7:S66.

40. Merle U, Schaefer M, Ferenci P, et al. Clinical presentation, diagnosis and long-term outcome of Wilson's disease: a cohort study. Gut 2007;56:115-20.

41. Dahlman T, Hartvig P, Löfholm M, et al. Long-term treatment of Wilson's disease with triethylene tetramine dihydrochloride (trientine). QJM 1995;88:609-16.

42. Brewer GJ, Askari F, Lorincz MT, et al. Treatment of Wilson disease with ammonium tetrathiomolybdate: IV. Comparison of tetrathiomolybdate and trientine in a double-blind study of treatment of the neurologic presentation of Wilson disease. Arch Neurol 2006;63:521-7.

43. Walshe JM. Treatment of Wilson's disease with trientine (triethylene tetramine) dihydrochloride. Lancet 1982;1:643-7.

44. European Medicines Agency. Trientine tetrahydrochloride - CHMP assessment report Cuprior - procedure No. EMEA/H/C/004005/0000, (2017). Available online: https://www.ema.europa.eu/en/documents/assessment- 
report/cuprior-epar-public-assessment-report_en.pdf

45. Brewer GJ, Dick RD, Johnson VD, et al. Treatment of Wilson's disease with zinc: XV long-term follow-up studies. J Lab Clin Med 1998;132:264-78.

46. Camarata MA, Ala A, Schilsky ML. Zinc Maintenance Therapy for Wilson Disease: A Comparison Between Zinc Acetate and Alternative Zinc Preparations. Hepatol Commun 2019;3:1151-8.

47. Weiss KH, Gotthardt DN, Klemm D, et al. Zinc monotherapy is not as effective as chelating agents in treatment of Wilson disease. Gastroenterology 2011;140:1189-1198.e1.

48. Ranucci G, Di Dato F, Spagnuolo MI, et al. Zinc monotherapy is effective in Wilson's disease patients with mild liver disease diagnosed in childhood: a retrospective study. Orphanet J Rare Dis 2014;9:41.

49. Weiss KH, Askari FK, Czlonkowska A, et al. Bischoline tetrathiomolybdate in patients with Wilson's disease: an open-label, multicentre, phase 2 study. Lancet Gastroenterol Hepatol 2017;2:869-76.

50. Stremmel W. Bis-choline tetrathiomolybdate as old drug in a new design for Wilson's disease: Good for brain and liver? Hepatology 2019;69:901-3.

51. Brewer GJ, Askari F, Dick RB, et al. Treatment of Wilson's disease with tetrathiomolybdate: $V$. Control of free copper by tetrathiomolybdate and a comparison with trientine. Transl Res 2009; 154:70-7.

52. Weiss KH, Schäfer M, Gotthardt DN, et al. Outcome and development of symptoms after orthotopic liver transplantation for Wilson disease. Clin Transplant 2013;27:914-22.

53. Lankarani KB, Malek-Hosseini SA, Nikeghbalian S, et al. Fourteen Years of Experience of Liver Transplantation for Wilson's Disease; a Report on 107 Cases from Shiraz, Iran. PLoS One 2016;11:e0167890.

54. Terada K, Nakako T, Yang XL, et al. Restoration of holoceruloplasmin synthesis in LEC rat after infusion of recombinant adenovirus bearing WND cDNA. J Biol Chem 1998;273:1815-20.

55. Merle U, Encke J, Tuma S, et al. Lentiviral gene transfer ameliorates disease progression in Long-Evans cinnamon rats: an animal model for Wilson disease. Scand J Gastroenterol 2006;41:974-82.

56. Merle U, Stremmel W, Encke J. Perspectives for gene therapy of Wilson disease. Curr Gene Ther 2007;7:217-20.

57. Moreno D, Murillo O, Gazquez C, et al. Visualization of the therapeutic efficacy of a gene correction approach in Wilson's disease by laser-ablation inductively coupled mass spectrometry. J Hepatol 2018;68:1088-90.

58. Murillo O, Luqui DM, Gazquez C, et al. Long-term metabolic correction of Wilson's disease in a murine model by gene therapy. J Hepatol 2016;64:419-26.

59. Murillo O, Moreno D, Gazquez C, et al. Liver Expression of a MiniATP7B Gene Results in Long-Term Restoration of Copper Homeostasis in a Wilson Disease Model in Mice. Hepatology 2019;70:108-26.

60. Uerlings R, Moreno D, Murillo O, et al. Brain copper storage after genetic long-term correction in a mouse model of Wilson disease. Neurol Genet 2018;4:e243.

61. Tremmel R, Uhl P, Helm F, et al. Delivery of Copperchelating Trientine (TETA) to the central nervous system by surface modified liposomes. Int J Pharm 2016;512:87-95.

62. Ferenci P, Steindl-Munda P, Vogel W, et al. Diagnostic value of quantitative hepatic copper determination in patients with Wilson's Disease. Clin Gastroenterol Hepatol 2005;3:811-8.

63. Cope-Yokoyama S, Finegold MJ, Sturniolo GC, et al. Wilson disease: histopathological correlations with treatment on follow-up liver biopsies. World J Gastroenterol 2010;16:1487-94.

64. Griesmann GE, Hartmann AC, Farris FF. Concentrations and correlations for eight metals in human liver. Int J Environ Health Res 2009;19:231-8.

65. McQuaid A, Lamand M, Mason J. The interactions of penicillamine with copper in vivo and the effect on hepatic metallothionein levels and copper/zinc distribution: the implications for Wilson's disease and arthritis therapy. J Lab Clin Med 1992;119:744-50.

66. Schaefer C, Weber-Schoendorfer. Drugs during pregnancy and lactation (3rd edition); Chapter 2.12: Immunosuppression, rheumatic diseases, multiple sclerosis, and Wilson's disease. Elsevier (ISBN: 978-0-12-4080782); 2015. p. 341-72.

67. Mattioli CA, Tomasi TB Jr. The life span of IgA plasma cells from the mouse intestine. J Exp Med 1973;138:452-60.

68. Lönnerdal B. Dietary factors influencing zinc absorption. J Nutr 2000;130:1378S-83S.

Cite this article as: Stremmel W, Weiskirchen R. Therapeutic strategies in Wilson disease: pathophysiology and mode of action. Ann Transl Med 2021;9(8):732. doi: 10.21037/atm-20-3090 